\title{
A REDESCRIPTION AND GENERIC REASSIGNMENT OF THE ADULTS OF HALOTANYTARSUS TIKA TOURENQ, 1975 (DIPTERA : CHIRONOMIDAE)
}

by P.S. CRANSTON ${ }^{1}$

The adult male of Halotanytarsus tika Toureng is redescribed and the female described for the first time. The taxonomic position of the species is discussed and the genus is placed as a junior synonym of Tanytarsus v.d. Wulp.

\section{Redescription et nouvelle position générique des imagos de Halotanytarsus tika Tourenq 1975 (Diptera, Chironomidae).}

L'imago $\sigma^{\top}$ de Halotanytarsus tika Tourenq est redécrite et l'imago $q$ décrite pour la première fois. La position taxonomique de l'espèce est discutée et le genre placé en synonymie avec Tanytarsus v.d. Wưlp.

\section{INTRODUCTION}

In 1966 Tourenq listed an undescribed genus Halotanytarsus in an introductory list of species from fresh and brackish waters of the Camargue in Southern France. Although certain diagnostic characters were given : « ... réduction des palpes labiaux et des tarses de la deuxième paire des pattes... » there were no named species included. Two years later Laville and Tourenq recorded adult Halotanytarsus sp. in flight from May until August in the Camargue.

In his doctoral thesis in 1975 Tourenq named the new species tika in the combination Halotanytarsus tika. This thesis appears to satisfy the criteria of publication (Articles 8 and 9 of the I.C.Z.N.). The generic name Halotanytarsus is valided by the citation of characters differentiating the taxon: “... caractérisés par une réduction des métatarses de la patte moyenne..." and by the designation of tika as type-species by monotypy. One year later (1976) Tourenq repeated the information presented in 1975 with no further description of the species. A footnote in the two previously mentioned publications states that a description of the new species would soon be published.

1. British Museum (National History), Cromwell Road London SW 75 BD. 
The discovery of further specimens of this species from Turkey and Crete makes this an opportune time for the publication of a fuller description of the species and an assessment of the generic position of tika Tourenq.

The author wishes to thank Dr. J.-N. Tourenq, Université PaulSabatier, Toulouse and Dr. F. Reiss, Zoologische Staatssammlung, Munich for the loan of specimens from their collections.

Tanytarsus tika (Tourenq, 1975) Comb. nov.

"Halotanytarsus" sp. Tourenq, 1966 : 464 Nom. nud. (I.C.Z.N. 13 b).

"Halotanytarsus" sp. Laville \& Tourenq, $1968: 77$ Nom. nud. (I.C.Z.N. 13 b).

Halotanytarsus tika Tourenq, 1975: 204.

Halotanytarsus tika Tourenq, 1976: 63.

\section{MATERIAL EXAMINED}

1 f [Slide mounted in Euparal] France : Bouches-du-Rhône, Camargue, J.-N. Tourenq, Université Paul-Sabatier, Toulouse. Lectotype here designated.

Paralectotypes 17 8, 4 \% [Slide mounted in Euparal or Berlese]. Same data as lectotype. Deposited in the Universite Paul-Sabatier and the British Museum (Natural History), London.

5 o [Slide mounted in Euparal]. GreEce : Confu, Kurnas -See, $50 \mathrm{~m}$. a.s.l. $24^{\circ} 16^{\prime}$ E. $35^{\circ} 20^{\prime}$ N. 16.v.1971, To light, H. Malicky. Staatssammlung Munich.

4 f, 3 q [Slide mounted in Berlese]. Turkey : Konya, Hortu, $8 \mathrm{kms}$. N.W. Ereğli, 980 m. a.s.1. $33^{\circ} 83^{\prime}$ E. $37^{\circ} 55^{\prime}$ N., 10.viii.1974, To light beside saline drainage ditch, P.S. Cranston, B.M. 1974 - 482. British Museum Natural History).

Male $(\mathrm{n}=26$ ). Length 2.4-3.4 m.m., wing length 1.3-1.7 m.m.

Antenna. Pale yellow, antennal plume slightly reduced. Pedicel $55 \mu$ high $\times 95 \mu$ wide. 13 flagellomeres : length (in $\mu$ ) 40, 18, 18, 22, $27,29,31,31,34,33,32,35,186$. Antennal ratio $0.48-0.57(0.53)$.

Head. Yellow. Frontal tubercles $25-32 \mu$ long. Palps pale, 5 segmented : 1st $26 \mu$ long $\times 21 \mu$ wide, 2nd $26 \mu \times 26 \mu$, 3rd $31 \mu \times 29 \mu$, 4th $34 \mu \times 26 \mu$, 5th $45 \mu \times 18 \mu$. 6-8 temporal setae in a single row of 2-3 postorbitals, 2-3 outer verticals and 1-2 inner verticals. Clypeus with 15-21 bristles. Eyes bare with only slight dorsal elongation. Cibarial pump as in Fig. 1 a, tentorium as in Fig. 1 b.

Thorax. Greenish-yellow, halteres pale yellow. Antepronotum 

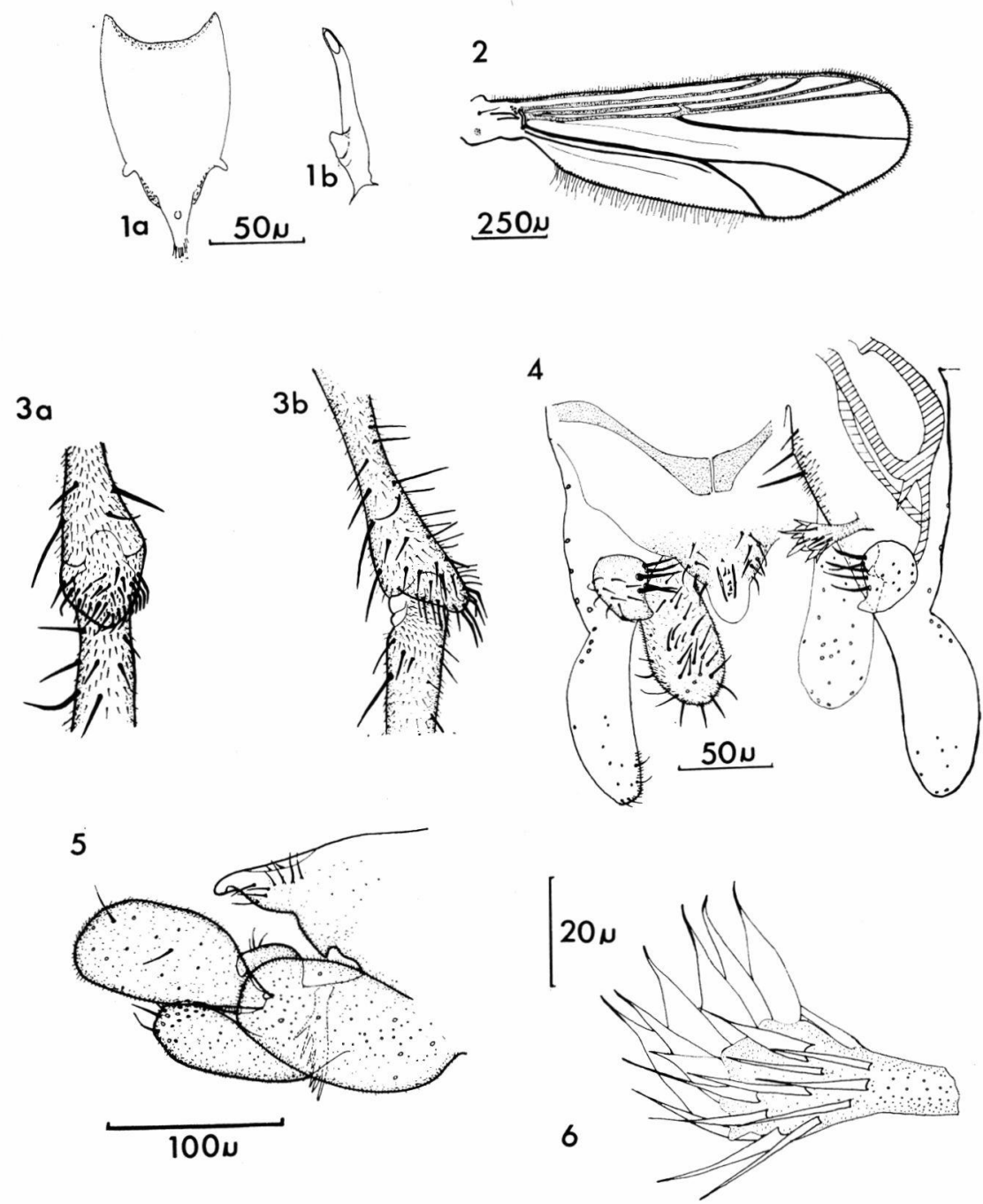

Fig. 1 to 6. - Fig. 1a. Cibarial pump, labial lonchus, cornua and tormae. Fig. $1 \mathrm{~b}$. $\sigma^{\circ}$ Tentorium. Fig. 2. $\sigma^{\circ}$ Wing. Fig. 3a. Tibial pad of P, of $\sigma^{\circ}$. Fig. 3b. Tibial pad of $\mathrm{P}_{3}$ of $\sigma^{*}$. Fig. 4. $\sigma^{*}$ Hypopygium (Dorsal). Fig. $5 \sigma^{*}$ Hypopygium (Lateral). FIG. 6. Appendage 2 a squashed (phase contrast).

bare, lobes medially widely separated, invisible from above but broadened laterally. Acrostitials 1-2, dorsocentrals 1-3, prealars absent. Scutellum with $0-2$ setae.

Wing. Venation as in Fig. 2. Basal vein with one seta, remaining veins and membrane without microtrichia. Wing membrane finely punctate. V.R. 1.14-1.25 (1.19). Squama bare. 
Legs. P2 $40 \%$ P1, P3 $70 \%$ P1. Meso- and metatibial apices each with a setose pad (Fig. 3). Pulvillae and empodium about 15-20 $\mu$ long. Claw $25 \mu$ long. Mean proportions and lengths of the legs (in $\mu)$ excluding Crete specimens $(n=21)$ :

\begin{tabular}{lcccrrrrrl}
\hline Leg & Fe & Ti & Ta1 & Ta2 & Ta3 & Ta4 & Ta5 & L.R. & B.R. \\
\hline P1 & 647 & 490 & 615 & 335 & 289 & 238 & 143 & 1.26 & $0.8-1.2$ \\
P2 & 425 & 400 & 125 & 57 & 49 & 33 & 44 & 0.31 & $0.7-1.1$ \\
P3 & 570 & 489 & 276 & 170 & 195 & 121 & 80 & 0.56 & $0.7-1.1$ \\
\hline
\end{tabular}

The population from Crete has all segments of the legs between 25 and $40 \%$ longer than the others. The ratios are similar however.

Hypopygium (Figs. 4, 5 \& 6). Anal point $45-50 \mu$ long with a pair of combs and 4-6 (7-12 Crete) dorsal spines between the combs. 6-8 setae laterally on the anal point. Digitus of endomere (appendage $2 a$ ) as in Fig. 6 with lamellar setae ("blattborsten" of Reiss $1968: 210$ ). Five of the specimens from the Camargue show various degrees of torsion of the hypopygium, two showing full $180^{\circ}$ inversion.

Female $(\mathrm{n}=7)$. Length 2.3-3.3 m.m., wing length $1.3-1.7 \mathrm{~m} . \mathrm{m}$.

Antenna. Pedicel $50 \mu \times 84 \mu$. 4 flagellomeres, mean length in $\mu$ : 73, 35, 36, 147. Antennal ratio 0.9-1.1 (1.03) (Fig. 7).

Head. 6-8 temporal setae distributed as in the male. Clypeus with 18-25 bristles.

Palps five segmented : 1st $24 \mu \times 21 \mu$, 2nd $19 \mu \times 26 \mu$, 3rd $28 \mu \times 25 \mu$, 4th $28 \mu \times 22 \mu$, 5th $33 \mu \times 21 \mu$.

Thorax. As in male except that no scutellar bristles were seen in all the specimens examined.

Legs. P2 $70 \%$ P1, P3 $110 \%$ P1. Apices of tibias as in male. Mean proportions and lengths of legs (in $\mu$ ):

\begin{tabular}{ccccrrcccc}
\hline Leg & $\mathrm{Fe}$ & $\mathrm{Ti}$ & $\mathrm{Ta} 1$ & $\mathrm{Ta} 2$ & $\mathrm{Ta} 3$ & $\mathrm{Ta} 4$ & $\mathrm{Ta} 5$ & L.R. & B.R. \\
\hline P1 & 473 & 422 & 403 & 143 & 103 & 77 & 59 & 0.95 & $0.8-1.1$ \\
P2 & 415 & 421 & 160 & 52 & 37 & 23 & 32 & 0.38 & $0.7-0.9$ \\
P3 & 540 & 520 & 295 & 149 & 145 & 84 & 59 & 0.57 & $0.7-1.0$ \\
\hline
\end{tabular}

Genitalia (Figs. 8 \& 9). Gonocoxapodeme VIII (GCa) apparently absent. Notum twice length of seminal capsules but caudally faint. Sternite VIII (S) forms a large floor under the vagina. Gonapophysis VIII (Gp) simple, rounded bearing long $(40 \mu)$ microtrichia on caudal 

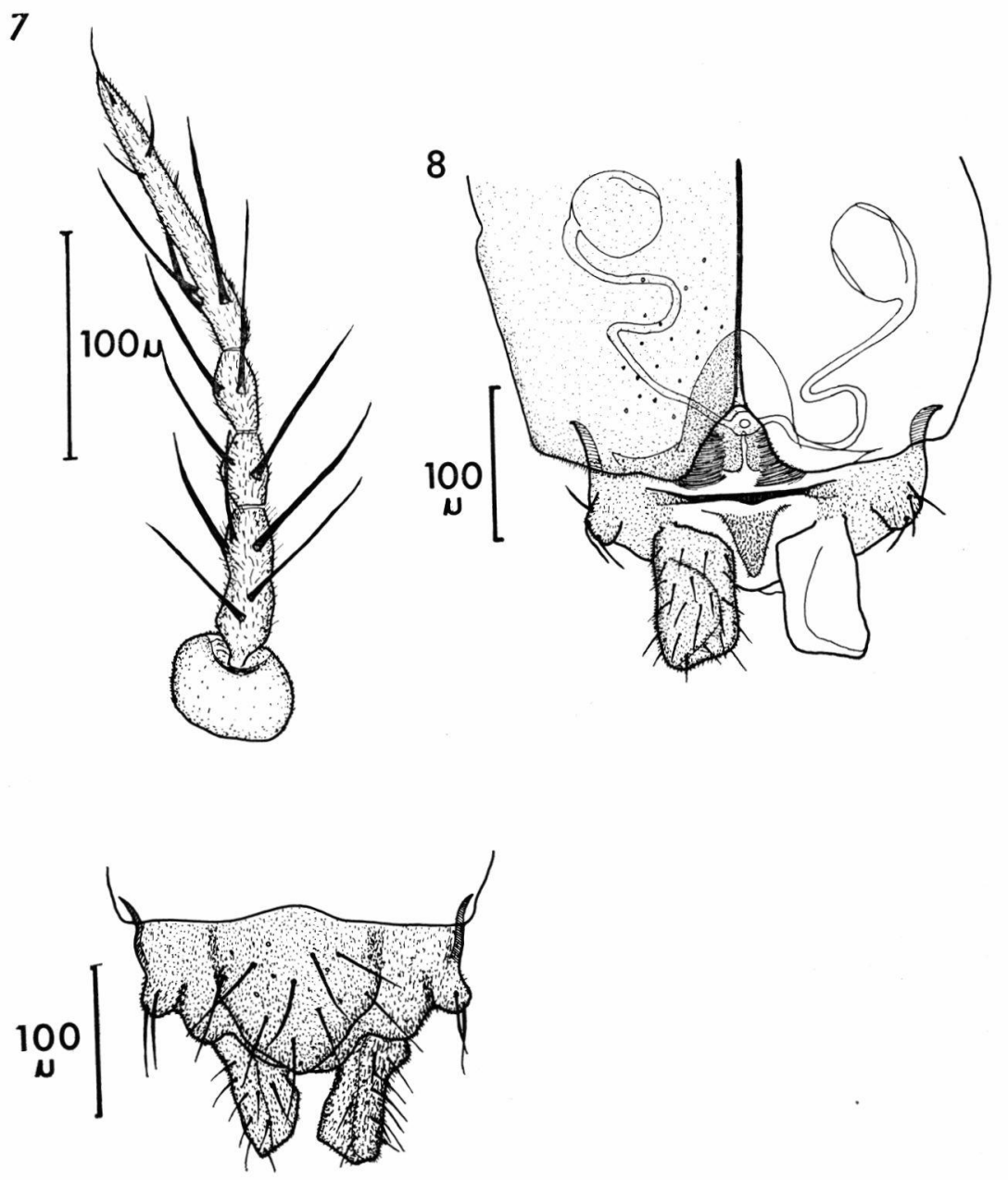

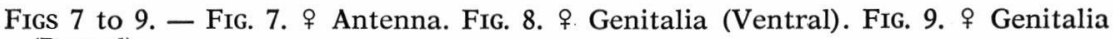
(Dorsal).

and caudomesal surfaces. Tergite IX (Fig. 9) bluntly triangular with moderately developed shoulders. Gonocoxite IX with 2-3 setae. Cerci relatively large. Postgenital plate distinct ( $40 \mu \mathrm{long}$ ) and triangular. Seminal capsules ovoid with no distinet necks. Spermathecal ducts sinuous. 


\section{SYSTEMATICS}

The bare squamae, horizontal vein $r-m$, foreleg ratio and hypopygium with four volsellae indicates that tika Toureng belongs to the tribe Tanytarsini of the subfamily Chironominae. Several genera in this tribe are described as lacking macrotrichia on the wings and without a comb on the meso- and metatibial apices: Himatendipes Tokunaga, 1959, Biwatendipes Tokunaga, 1965, Corynocera Zetterstedt, 1838, Thienemanniola Kieffer, 1921 and Lenziella Kieffer, 1922 (sensu Sæther, 1971 a).

T. tika (Tourenq) shares several other characters with some of these genera including shortened segments of the midleg, shortened palpal segments, reduced number of flagellomeres in the female and a reduction in the antennal plume of the male. However, as pointed out by Sæther (1971 a : 1824) these are atrophied, aberrant characters which are of limited use as generic characters. He further observes that these genera are apparently not closely related but are the aberrant forms of other common Tanytarsine genera, the relationships of which he discusses.

The explanation of the convergence of the phenotypes of these genera may be associated with mating on the ground. Tourenq (1976: 63) notes that the adults of tika do not form mating swarms but move at the water surface. Assuming that mating is not aerial, as seems likely, many characters may be seen as modifications for ground mating. Foremost among these is the facultative torsion of the hypopygium which permits end-to-end mating. Corynocera, Thienemanniola and two species of Tanytarsus, miriforceps and sylvaticus also exhibit hypopygial torsion (Fittkau 1971:29). Corynocera and Thienemanniola also share many of the aberrant characters listed for tika. Since ground mating can occur in unrelated genera, accompanied by parallelled modifications, atrophied characters associated with this behavioural change cannot be used in the generic placement of tika.

The male hypopygium, female genitalia and internal structures of the head should be characters unaffected by modification of the swarming habit and should give indications of the generic affinity. The hypopygium is like a typical Tanytarsus, possessing combs and spines on the anal point and simple, lamellar setae on the digitus of the endomere. Although the species shares many characters with the genus Lenziella the bifid or ramified bristles on the digitus of the endomere show that this latter genus has greater affinities with Cladotanytarsus Kieffer. The female genitalia are very similar to those of Tanytarsus spp. described and figured by Sæther (1977: 143, Figs. 64 \& $65 \mathrm{a}-\mathrm{c})$ except that the notum is longer in tika. This character seems 
to be more variable within the genus Tanytarsus than suggested by Saether, as shown by the examination of further British material of the genus.

Comparison of the cibarial pump and tentorium of tika with other species of Tanytarsus shows that the shape of these structure falls well within the variation shown by other non-aberrant species.

\section{SYNONYMY}

Tanytarsus Wulp, 1874: 134. Type-species signatus Wulp, 1858. (I.C.Z.N. 1961 :361.)

Halotanytarsus Tourenq, 1975 : 204. Type-species tika Tourenq, 1975 by monotypy. Syn. $n$.

\section{REFERENCES}

FitTKaU (E. J.). 1971. - Der Torsions-Mechanismus beim Chironomiden-Hypopygium. Limnologica, Berlin, 8 (1) : 227-34.

INTERnational Commission on zoological nomenclature 1961. - Opinion 616. Tanytarsus van der Wulp, 1874 (Insecta, Diptera). Designation of a type-species under the Plenary Powers. Internatl. Comm. Zool. Nomenc., Bull. zool. Nom., $18: 361-362$.

KiefFer (J. J.). 1921. - Notes sur quelques Chironomides étranges habitant les lacs de Schleswig-Holstein. C. r. Ass. fr. Advanc. Sci., (1920) : 327-331.

KIEFFER (J. J.). 1922. - Nouveaux chironomides à larves aquatiques. Annls Soc. scient. Brux., $41: 355-367$.

Laville (H.) \& Toureno (J.-N.). 1968. - Nouvelles récoltes de Chironomides en Camargue et dans les Marimas de Guadalquivir. Annls. Limnol., 4 (1) : 73-80.

Lehmann (J.). 1973. - Systematische und phylogenetische Studie über die Gattungen Thiennemanniola Kieffer und Corynocera Zetterstedt (Diptera, Chironomidae). Hydrobiologica, $43: 381-414$.

L.Indeberc (B.). 1970. - Tanytarsini (Diptera, Chironomidae) from Northern Fennoscandia. Annls. Zool. Fenn., $7:$ 303-312.

SAETHER (O. A.). 1971. - Notes on the general morphology and terminology of the Chironomidae (Diptera). Can. Ent., 103 : 1237-1260.

SAETHER (O. A.). 1971 a. - Four new and unusual Chironomidae (Diptera). Can. Ent., 103 : 1799-1827.

SAETHER (O. A.). 1977. - Female genitalia in Chironomidae and other nematocera: morphology, phylogenies and keys. Bull. Fish. Res. Bd. Can., 197-210.

ToKunaga (M.). 1959. - A new midge from Kashmir (Diptera, Tendipedidae). Akitu, 8: 21-23.

Tokunaga (M.). 1965. - A new midge from Japan (Diptera, Chironomidae). Kont $y \hat{u}$, 33 : $42-45$.

Toureno (J.M.). 1966. - Introduction à l'étude écologique des Chironomides des eaux douces et saumâtres de Camargue. Annls. Limnol., 2 (2) : 459-465.

Toureno (J.-N.). 1975. - Recherche écologique sur les Chironomides (Diptera) de Camargue. Doctorat thesis. Université Paul-Sabatier, Toulouse.

Toureno (J.-N.). 1976. - Recherche écologique sur les Chironomides (Diptera) de Camargue. 1. Etude faunistique et biogéographique. Annls Limnol., 12 (1) : $17-74$. 